\title{
Classification of the Binding Modes in Bovine Serum Albumin Using Terminally Substituted Alkane Analogues
}

\author{
Kô Takehara, ${ }^{* \dagger}$ Yuki Morinaga, ${ }^{*}$ Shinya Nakashima, ${ }^{*}$ Shiro Matsuoka, $* *$ \\ Hiroshi KAMAYA,*** and Issaku UEDA*** \\ *Department of Chemistry, Faculty of Sciences, Kyushu University, Ropponmatsu, Chuo, Fukuoka 810-8560, Japan \\ **Department of Environmental Science, Faculty of Science, Niigata University, Ikarashi, Niigata 950-2181, Japan \\ ***DVA Medical Center and School of Medicine, University of Utah, Salt Lake City, UT 84148, USA
}

\begin{abstract}
With the fluorescence probe of 8-anilino-1-naphthalenesulfonate (ANS), the binding modes of terminally substituted alkane analogues $\left(\mathrm{C}_{\mathrm{n}} \mathrm{X} ; \mathrm{X}=\mathrm{COOH}, \mathrm{OH}, \mathrm{CHO}, \mathrm{NH}_{3}, \mathrm{CONH}_{2}\right)$ to bovine serum albumin (BSA) were investigated using a competitive binding technique. The Scatchard plot of the fluorometric titration of BSA with ANS showed that the maximum binding number of ANS, $n_{\max }$, was 3.81, with the binding constant, $K_{\text {bnd }}$, of $1.42 \times 10^{6} \mathrm{~mol}^{-1} \mathrm{dm}^{3}$. The binding modes of $\mathrm{C}_{\mathrm{n}} \mathrm{X}$ to BSA were analyzed based on the fluorometric titration of the ANS and BSA mixture with $\mathrm{C}_{\mathrm{n}} \mathrm{X}$. $\mathrm{C}_{n} \mathrm{COOH}$ completely displaced the ANS bound to BSA, whereas $\mathrm{C}_{n} \mathrm{OH}$ and $\mathrm{C}_{n} \mathrm{CHO}$ displaced only about $40 \%$ of the ANS bound to BSA. In contrast, $\mathrm{C}_{\mathrm{n}} \mathrm{NH}_{2}$ and $\mathrm{C}_{\mathrm{n}} \mathrm{CONH}_{2}$ displaced very little bound ANS. By comparing these results, we classified the binding modes of $\mathrm{C}_{\mathrm{n}} \mathrm{X}$ to BSA into three types. Two of them are detectable with the ANS fluorescence and the remaining one is not detectable with the fluorescence.
\end{abstract}

(Received September 8, 2006; Accepted October 10, 2006; Published December 10, 2006)

\section{Introduction}

8-Anilino-1-naphthalenesulfonate (ANS) fluoresces strongly in hydrophobic solvents but is almost nonfluorescent in water. ${ }^{1}$ The fluorescence intensities of the ANS ions bound to proteins are nearly equal to those of ANS ions dissolved in organic solvents. The large increase of the fluorescence intensity of ANS ions, when bound to BSA in water, is attributed to binding to the hydrophobic domains of a protein. ${ }^{2-4}$ We denote these sites as the fluorescence-active sites. Despite extensive spectrofluorometric studies with ANS, clear understanding of the properties of the binding site in BSA is lacking. Though it is established that there are at least two types of ANS binding sites in a BSA molecule, uncertainties still remain as to the properties of each binding site. ${ }^{5-8}$

Inhalation anesthetics and alcohols are hydrophobic molecules and are considered to act by interacting with a number of proteins by hydrophobic interaction. ${ }^{9-11}$ Therefore, it is important to make clear the binding properties of the hydrophobic molecules to proteins to elucidate the anesthetic action on proteins. This study used spectrofluorometry of the ANS to analyze the binding of five types of alkane analogues, $\mathrm{C}_{\mathrm{n}} \mathrm{X}$, that is, alkylalcohols $\left(\mathrm{C}_{\mathrm{n}} \mathrm{OH}, n=8,10,12\right)$, alkylaldehyde $\left(\mathrm{C}_{\mathrm{n}} \mathrm{CHO}, n=7,9,11\right)$, alkylacids $\left(\mathrm{C}_{\mathrm{n}} \mathrm{COOH}, n=5,7,9,11\right)$, alkylamines $\left(\mathrm{C}_{\mathrm{n}} \mathrm{NH}_{2}, \quad n=8,10,12\right)$, and alkylamides $\left(\mathrm{C}_{\mathrm{n}} \mathrm{CONH}_{2}, n=7,9,11\right) . \mathrm{C}_{\mathrm{n}} \mathrm{COOH}$ are in anionic form in the aqueous solution of neutral $\mathrm{pH}$, whereas $\mathrm{C}_{\mathrm{n}} \mathrm{NH}_{2}$ and $\mathrm{C}_{\mathrm{n}} \mathrm{CONH}_{2}$ are in cationic form in the neutral $\mathrm{pH} .{ }^{12} \mathrm{C}_{\mathrm{n}} \mathrm{OH}$ and $\mathrm{C}_{\mathrm{n}} \mathrm{CHO}$ have no net charges in the usual $\mathrm{pH}$ range. We reported previously that these analogues acted on the protein function in a different

$\doteqdot$ To whom correspondence should be addressed.

E-mail: kou@rc.kyushu-u.ac.jp manner. ${ }^{13,14}$ We report here the classification of three types of binding sites in a BSA molecule, estimated by the ANS fluorescence. Two of these types are fluorescence-active for the ANS ions bound to BSA, whereas the remaining one is fluorescence-inactive and cannot be detected by the ANS fluorescence. This report will show that the terminal charge of the $\mathrm{C}_{\mathrm{n}} \mathrm{X}$ critically affects the displacement reaction of the ANS ions bound to the fluorescence-active sites in BSA with $\mathrm{C}_{\mathrm{n}} \mathrm{X} .{ }^{15-17}$ Hydrophobicity of the $C_{n} X$ is also suggested to be another key factor to differentiate the binding sites in BSA. It is demonstrated that the three types of the binding sites in BSA can be classified by the competitive binding measurements of the ANS ions and alkane analogues. ${ }^{18-20}$

\section{Experimental}

\section{Materials and sample preparation}

Essentially fatty acid free bovine serum albumin (Cat. No. A7511) was purchased from Sigma Chemical Co. (St. Louis, USA) and used as supplied. An ammonium salt of 8-anilino-1naphthalenesulfonic acid (ANS $\cdot \mathrm{NH}_{4}$ ) was purchased from Tokyo Kasei Kogyo (Tokyo, Japan). Terminally substituted alkane analogues were purchased from Tokyo Kasei Kogyo, Aldrich Chemical Co. (Milwaukee, USA) or Acros Organics (New Jersey, USA) and were used without further purification. Sample solutions were prepared using the water purified by a MiliQ-SP reagent water system. Stock solutions of $5 \mathrm{mg} \mathrm{cm}^{-3}$ BSA and $2 \mathrm{mmol} \mathrm{dm}^{-3}$ ANS were prepared by dissolving BSA and ANS. $\mathrm{NH}_{4}$, respectively, into purified water containing 0.1 mol dm ${ }^{-3}$ glycylglycine buffer of $\mathrm{pH}$ 7.4. The concentrations of BSA and ANS were calibrated by UV/VIS absorbance using the molar absorption coefficient at $280 \mathrm{~nm}$ of $4.36 \times 10^{4} \mathrm{~cm}^{-1} \mathrm{~mol}^{-1}$ $\mathrm{dm}^{3}$ and the molecular weight 65500 for BSA and the molar 


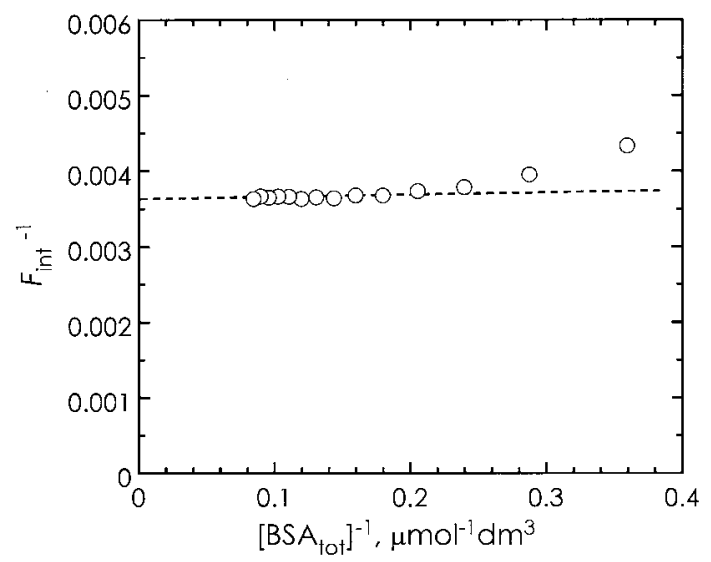

Fig. 1 Double reciprocal plot of the fluorescence intensity of ANS, $F_{\text {int, }}$ versus the total concentration of BSA, [BSA $\left.\mathrm{Btot}_{\text {tot }}\right]$. ANS $(10.3 \mu \mathrm{mol}$ $\mathrm{dm}^{-3}$ ) was titrated with BSA to obtain the fluorescence intensity of the ANS bound to BSA (ANS-BSA). The quantum yield of the ANS-BSA obtained from the extrapolation to the infinite BSA concentration was 0.46 , based on quinine as the standard.

absorption coefficient at $350 \mathrm{~nm}$ of $5.83 \times 10^{3} \mathrm{~cm}^{-1} \mathrm{~mol}^{-1} \mathrm{dm}^{3}$ for ANS. The absorbance was measured with a Shimadzu RF2200 UV/VIS spectrophotometer.

The $\mathrm{pH}$ values of all sample solutions were adjusted to 7.4 with $0.1 \mathrm{~mol} \mathrm{dm}^{-3}$ glycylglycine buffer. For fluorescence measurements, an aliquot of BSA and ANS stock solutions were mixed, diluted to desired concentration and kept standing for at least $15 \mathrm{~min}$ at $25^{\circ} \mathrm{C}$ to equilibrate the binding reaction before measurements.

\section{Fluorescence measurements}

Fluorescence was measured using a Shimadzu RF-5000 fluorescence spectrophotometer equipped with a temperaturecontrolled cell holder. The cell temperature was controlled at $25 \pm 0.2^{\circ} \mathrm{C}$ by a NESLAB RTE- 8 circulation water bath. The excitation wavelength was $352 \mathrm{~nm}$ and emission spectra were recorded between $460 \mathrm{~nm}$ and $480 \mathrm{~nm}$. The peak wavelengths of the emission spectra were observed at around $471 \mathrm{~nm}$.

To avoid the concentration quenching of the fluorophore, we kept the ANS concentrations below $2 \times 10^{-5} \mathrm{~mol} \mathrm{dm}^{-3}$. Under this concentration, a linear relationship between the fluorescence intensity and ANS concentration was confirmed by measuring the ANS fluorescence in $n$-propanol.

The fluorescence quantum yield of the ANS bound to BSA, ANS-BSA, was estimated using quinine sulfate as the standard. The absorbance and fluorescence intensities of ANS-BSA solution were compared to those of quinine sulfate solution. The quantum yield of the quinine sulfate in $1.0 \mathrm{~mol} \mathrm{dm}^{-3} \mathrm{H}_{2} \mathrm{SO}_{4}$ was taken as 0.55 at $25^{\circ} \mathrm{C}$.

\section{Displacement measurements}

The displacement of the ANS on BSA with $\mathrm{C}_{\mathrm{n}} \mathrm{X}$ was estimated by adding an aliquot of $\mathrm{C}_{\mathrm{n}} \mathrm{X}$ solution into the mixture of $0.75 \mu \mathrm{mol} \mathrm{dm}{ }^{-3}$ BSA and $10.0 \mu \mathrm{mol} \mathrm{dm}{ }^{-3}$ ANS. A $0.03-\mathrm{cm}^{3}$ volume of the ethanolic solution of $\mathrm{C}_{\mathrm{n}} \mathrm{X}$ was added to $3.0 \mathrm{~cm}^{3}$ of the mixture of ANS and BSA in $0.1 \mathrm{~mol} \mathrm{dm}^{-3}$ buffer solution of $\mathrm{pH}$ 7.4. The decrease of the fluorescence intensity caused by the addition of $\mathrm{C}_{\mathrm{n}} \mathrm{X}$ was recorded as the measure of the displacement of the ANS on BSA with $\mathrm{C}_{\mathrm{n}} \mathrm{X}$.

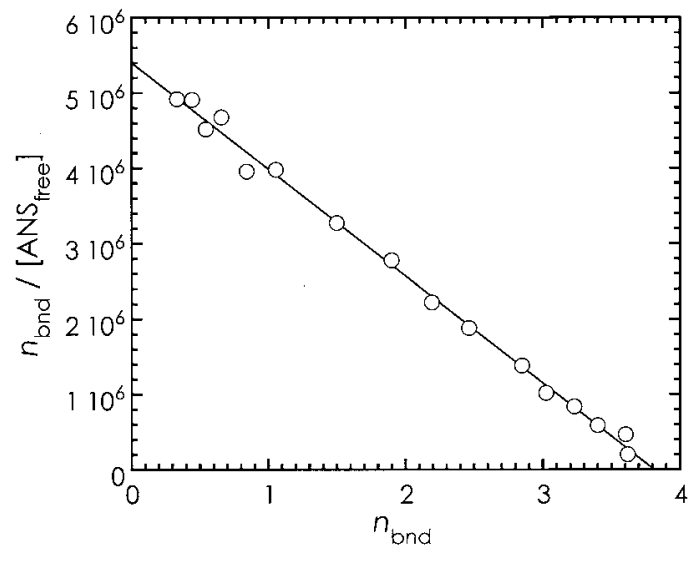

Fig. 2 Scatchard plot of the fluorescence titration of BSA with ANS. BSA $\left(0.74 \mu \mathrm{mol} \mathrm{dm}^{-3}\right)$ was titrated with ANS. The maximum binding number, $n_{\max }$, and the binding constant, $K_{\mathrm{bnd}}$, of the ANS to BSA were estimated from the slope and $\mathrm{X}$-axis intercept and were 3.81 and $1.42 \times 10^{6}$, respectively.

\section{Results and Discussion}

\section{Fluorescence intensity of the ANS bound to BSA}

The fluorescence intensity of the ANS-BSA was estimated by the following procedure. Under the ANS concentration fixed at $10.3 \mu \mathrm{mol} \mathrm{dm}^{-3}$, the double reciprocal plot between the fluorescence intensity versus the total BSA concentration is shown in Fig. 1. The maximum fluorescence intensity was obtained by extrapolating the linear regression line to infinite BSA concentration. This value is assigned to the fluorescence intensity of the ANS-BSA under the condition that all ANS ions in solution are bound to the BSA molecules. The molar fluorescence intensity of the ANS on BSA was obtained by dividing the maximum fluorescence intensity of the ANS-BSA by the ANS concentration. The molar fluorescence intensity was converted further to the quantum yield using the quantum yield 0.55 of quinine sulfate as the standard. ${ }^{21}$ In these procedures, we assumed that the fluorescence intensities of all bound ANS are equivalent and independent of the binding site in BSA. The quantum yield of the ANS-BSA thus obtained was 0.46 , which agrees well with the reported values $0.42-0.48$ for the ANS bound to proteins.22 This result supports the validity of the assumption of the equivalent fluorescence intensity for all bound ANS ions.

\section{Binding of ANS to BSA}

The maximum binding number of ANS to BSA, $n_{\max }$, and the binding constant, $K_{\text {bnd, }}$, were estimated by the fluorometric titration of $0.74 \mu \mathrm{mol} \mathrm{dm}{ }^{-3}$ BSA with ANS solution. Figure 2 shows the Scatchard analysis of the titration data. A straight line was obtained with $n_{\max } 3.81$ and $K_{\text {bnd }} 1.42 \times 10^{6} \mathrm{~mol}^{-1} \mathrm{dm}^{3}$. The linearity of the Scatchard plot and the $n_{\max }$ value of 3.81 indicate the existence of four binding sites in a BSA molecule with similar affinity to ANS ions. These values agree well with those reported by several authors, in which $n_{\max }$ and $K_{\text {bnd }}$ values were in the ranges of 3 to 5 and $2.1 \times 10^{5}$ to $2.9 \times 10^{6}$, respectively. ${ }^{23-25}$

Even more ANS binding sites on BSA were reported by Kolb and Weber $^{26}$ and Valsami. ${ }^{27}$ These sites are identified by equilibrium dialysis and potentiometry but not detectable by fluorescence measurement. Therefore, these sites are considered to be hydrophilic enough that water molecules can 


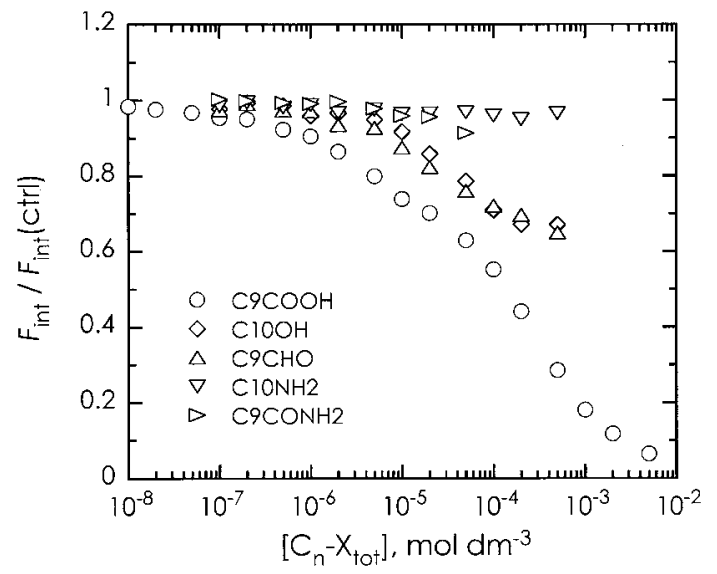

Fig. 3 Dependence of the relative fluorescence intensity of ANSBSA, $F_{\text {int }} / F_{\text {int }}(\mathrm{ctrl})$, on the total concentration of decane analogues, $\left[\mathrm{C}_{\mathrm{n}}-\mathrm{X}_{\mathrm{tot}}\right]$, at $\mathrm{pH}$ 7.4. The concentrations of ANS and BSA were 10.3 and $0.74 \mu \mathrm{mol} \mathrm{dm}{ }^{-3}$, respectively. $\mathrm{C}_{9} \mathrm{COOH}$ entirely quenched the fluorescence of ANS-BSA. $\mathrm{C}_{10} \mathrm{OH}$ and $\mathrm{C}_{9} \mathrm{CHO}$ decreased the fluorescence intensity about $40 \%$ of the initial intensity at their saturated concentrations. $\mathrm{C}_{10} \mathrm{NH}_{2}$ and $\mathrm{C}_{9} \mathrm{CONH}_{2}$ decreased the fluorescence not more than $20 \%$ of the initial intensity.

gain access to the bound ANS ions to quench their fluorescence. Furthermore, the reported binding capacity of these sites is more than ten ANS ions in a BSA molecule, far larger than the capacity of fluorescence-active sites of 3 to 5 .

\section{Displacement of the bound ANS with $C_{n} X$}

Figure 3 shows the fluorescence intensities of the ANS-BSA when $\mathrm{C}_{9} \mathrm{COOH}, \mathrm{C}_{10} \mathrm{OH}, \mathrm{C}_{9} \mathrm{CHO}, \mathrm{C}_{10} \mathrm{NH}_{2}$, or $\mathrm{C}_{9} \mathrm{CONH}_{2}$ is added to the aqueous solution of $10.3 \mu \mathrm{mol} \mathrm{\textrm {dm } ^ { - 3 }}$ ANS and $0.74 \mu \mathrm{mol}$ $\mathrm{dm}^{-3}$ BSA mixture at $\mathrm{pH}$ 7.4. In Fig. 3, the relative fluorescence intensity was taken as the fluorescence intensity of the ANS in the presence of $\mathrm{C}_{\mathrm{n}} \mathrm{X}$ divided by the fluorescence intensity in the absence of $\mathrm{C}_{\mathrm{n}} \mathrm{X}$. These alkane analogues are classified in the three different types depending on the inhibition effect on the ANS fluorescence. $\mathrm{C}_{9} \mathrm{COOH}$ (group-I*) inhibited the fluorescence intensity most effectively. It almost entirely quenched the fluorescence intensity of the ANS-BSA in a dosedependent manner. In addition, the plot showed two distinguishable segments with the inflection point at the $\mathrm{C}_{9} \mathrm{COOH}$ concentration about $10^{-5} \mathrm{~mol} \mathrm{dm}^{-3} . \mathrm{C}_{10} \mathrm{OH}$ and $\mathrm{C}_{9} \mathrm{CHO}$ (group-II) inhibited only about $40 \%$ of the fluorescence at their highest soluble concentrations. There are two types of the fluorescence-active ANS binding sites in a BSA: one is competitive to group-II alkane analogues, and the other is noncompetitive. $\mathrm{C}_{10} \mathrm{NH}_{2}$ and $\mathrm{C}_{9} \mathrm{CONH}_{2}$ (group-III) inhibited the fluorescence intensity very little even at their highest soluble concentrations.

Assuming that all the fluorescence-active sites in BSA are occupied by either of ANS or $\mathrm{C}_{\mathrm{n}} \mathrm{X}$, we estimated the amount of $\mathrm{C}_{\mathrm{n}} \mathrm{X}$ bound to BSA from the decrease of the ANS fluorescence. Figures 4 to 8 show the site occupancies of $\mathrm{C}_{\mathrm{n}} \mathrm{X}$ thus obtained as a function of free $\mathrm{C}_{n} \mathrm{X}$ concentration for $\mathrm{C}_{n} \mathrm{COOH}, \mathrm{C}_{\mathrm{n}} \mathrm{OH}$, $\mathrm{C}_{\mathrm{n}} \mathrm{CHO}, \mathrm{C}_{\mathrm{n}} \mathrm{NH}_{2}$, and $\mathrm{C}_{\mathrm{n}} \mathrm{CONH}_{2}$, respectively. The site occupancy, $\theta$, is defined as the number of the bound $\mathrm{C}_{\mathrm{n}} \mathrm{X}$ divided by the number of the fluorescence-active binding sites in a BSA. In these figures, the results for the different alkyl chain-length of $\mathrm{C}_{\mathrm{n}} \mathrm{X}$ are also plotted. For all alkane analogues examined, the displacement began to occur at lower $\mathrm{C}_{\mathrm{n}} \mathrm{X}$ concentrations with the increase of the alkyl chain-length.

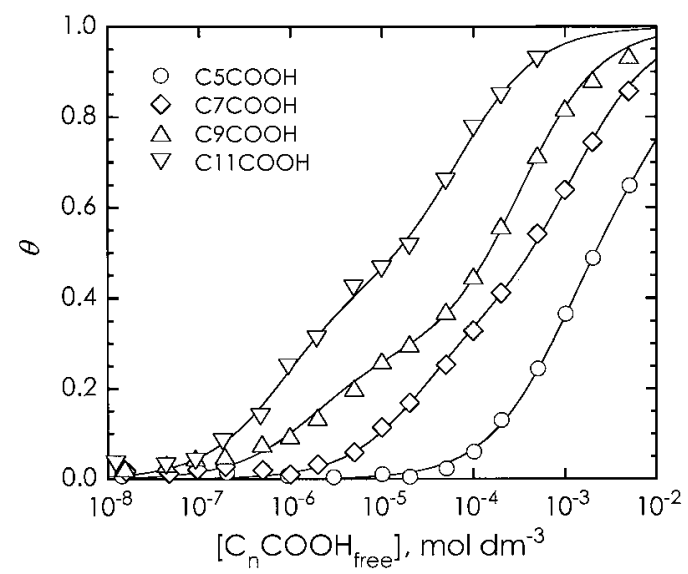

Fig. 4 Dependences of the concentration of free $\mathrm{C}_{\mathrm{n}} \mathrm{COOH}(n=5,7$, $9,11)$ on the site occupancy, $\theta$, of $\mathrm{C}_{\mathrm{n}} \mathrm{COOH}$ in BSA. The concentrations of ANS and BSA were 10.3 and $0.74 \mu \mathrm{mol} \mathrm{dm}^{-3}$, respectively. All of $\mathrm{C}_{\mathrm{n}} \mathrm{COOH}$ entirely displaced the ANS bound to the fluorescence-active sites in BSA, though the concentration required for the entire displacement increased with decreasing the alkyl chain-length. Moreover, the binding curves can be divided in two segments. We classify the $\mathrm{C}_{n} \mathrm{COOH}$ as the group-I analogues.

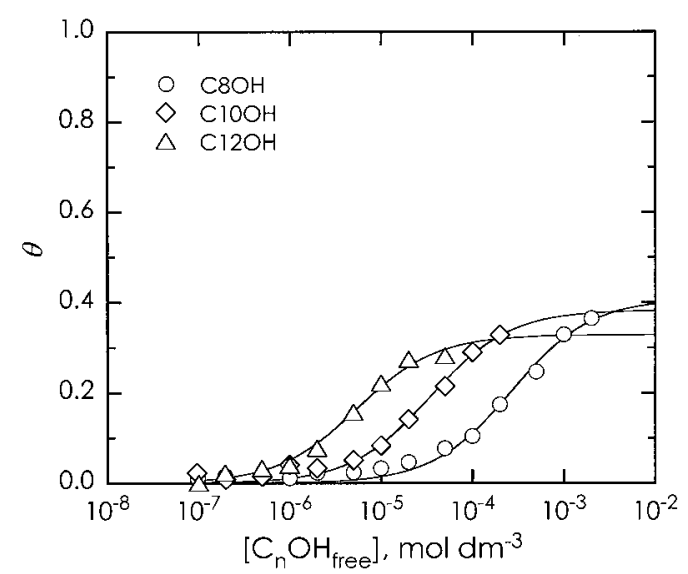

Fig. 5 Dependences of the concentration of free $\mathrm{C}_{n} \mathrm{OH}(n=8,10$, 12) on the site occupancy, $\theta$, of $\mathrm{C}_{n} \mathrm{OH}$ in BSA. All of $\mathrm{C}_{n} \mathrm{OH}$ displaced only about $40 \%$ of the ANS bound to the fluorescenceactive sites in BSA at their saturated concentrations.

However, the maximum displacement at higher concentration was almost independent of the alkyl chain-length. All group-I analogues almost entirely displaced the ANS on BSA. Moreover, the binding profiles in Fig. 4 show the inflection point at the occupancy of around $40 \%$. This inflection point, however, faded gradually with the decrease of the alkyl chainlength of $\mathrm{C}_{\mathrm{n}} \mathrm{COOH}$. In contrast, all group-II analogues displaced only about $40 \%$ of the ANS on BSA, and the remaining $60 \%$ of the bound ANS were unaffected. The effects of group-III analogues were not more than $17 \%$ of the bound ANS. The results of the group-I and group-II analogues suggest the existence of two different types of the fluorescence-active sites in BSA. These two types of the binding sites in BSA, however, cannot be distinguished by the direct measurement of

* We categorize the three types of terminally-substituted alkane analogues as group-I $\left(\mathrm{C}_{n} \mathrm{COOH}\right)$, group-II $\left(\mathrm{C}_{\mathrm{n}} \mathrm{OH}\right.$ and $\left.\mathrm{C}_{\mathrm{n}} \mathrm{CHO}\right)$, and group-III $\left(\mathrm{C}_{\mathrm{n}} \mathrm{NH}_{2}\right.$ and $\left.\mathrm{X}_{\mathrm{n}} \mathrm{CONH}_{2}\right)$. 


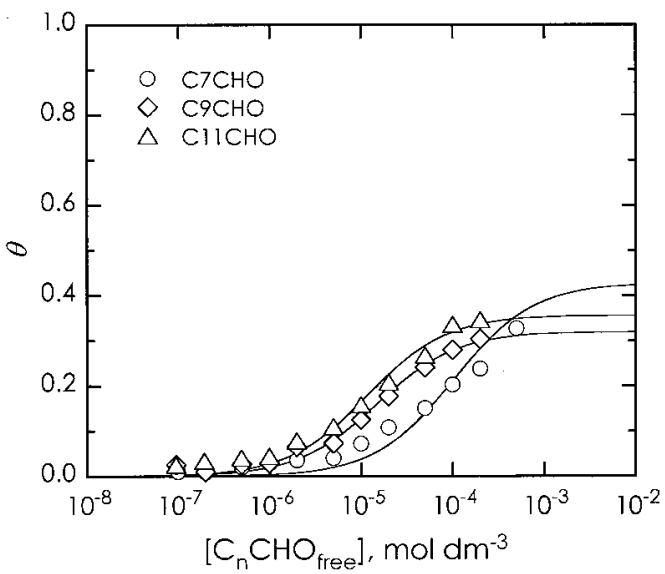

Fig. 6 Dependences of the concentration of free $\mathrm{C}_{n} \mathrm{CHO}(n=7,9$, 11) on the site occupancy, $\theta$, of $\mathrm{C}_{\mathrm{n}} \mathrm{CHO}$ in BSA. All of $\mathrm{C}_{\mathrm{n}} \mathrm{CHO}$ displaced only about $40 \%$ of the ANS bound to the fluorescenceactive sites in BSA at their saturated concentrations, similar to the case of $\mathrm{C}_{n} \mathrm{OH} . \quad \mathrm{C}_{\mathrm{n}} \mathrm{OH}$ and $\mathrm{C}_{\mathrm{n}} \mathrm{CHO}$ are classified as group-II analogues.

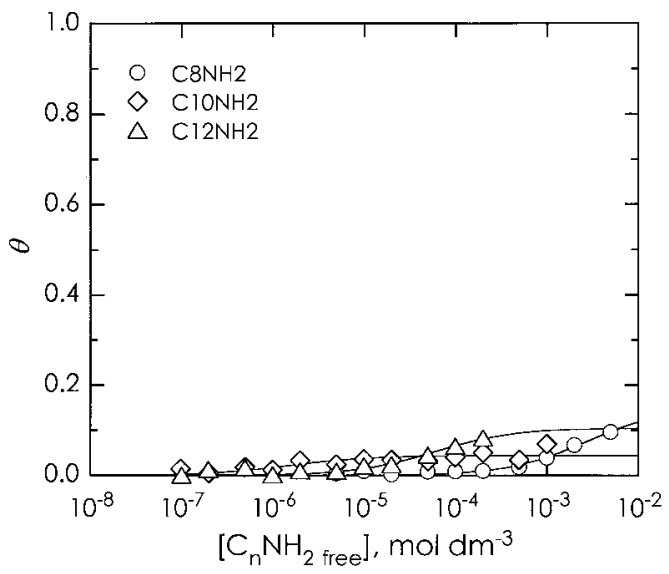

Fig. 7 Dependences of the concentration of free $\mathrm{C}_{\mathrm{n}} \mathrm{NH}_{2}(n=8,10$, 12 ) on the site occupancy, $\theta$, of $\mathrm{C}_{n} \mathrm{NH}_{2}$ in BSA. These amines only slightly decreased the fluorescence intensity of the ANS bound to BSA even at their saturated concentrations.

the ANS binding to BSA as shown in Fig. 2.

The solid lines in Figs. 4 to 8 were obtained by a nonlinear least-square curve-fitting method with the following two assumptions: (1) There are two different types of $\mathrm{C}_{\mathrm{n}} \mathrm{X}$ binding sites in BSA. One type binds all analogues of group-I to groupIII, whereas the other binds only the group-I analogues. (2) The binding of $\mathrm{C}_{\mathrm{n}} \mathrm{X}$ obeys the Langmuir binding isotherm. With these assumptions, the curve fitting was performed using the following equations. For the binding of group-I analogues, the site occupancy, $\theta$, is expressed as a function of free $C_{n} X$ concentration, $\left[\mathrm{C}_{\mathrm{n}} \mathrm{X}_{\text {free }}\right]$, according to the Langmuir binding isotherm for two types of independent sites, ${ }^{15}$

$$
\theta=\frac{\eta_{1} K_{1}\left[\mathrm{C}_{\mathrm{n}} \mathrm{X}_{\text {free }}\right]}{1+K_{1}\left[\mathrm{C}_{\mathrm{n}} \mathrm{X}_{\text {free }}\right]}+\frac{\eta_{2} K_{2}\left[\mathrm{C}_{\mathrm{n}} \mathrm{X}_{\text {free }}\right]}{1+K_{2}\left[\mathrm{C}_{\mathrm{n}} \mathrm{X}_{\text {free }}\right]}
$$

in which subscripts 1 and 2 signify two types of the binding sites, site- 1 and site- 2 , in BSA, and $\eta$ and $K$ are the fraction of each site and the binding constant, respectively. By using the experimental values of $\theta$ and $\left[\mathrm{C}_{\mathrm{n}} \mathrm{X}_{\text {free }}\right]$, we can estimate the

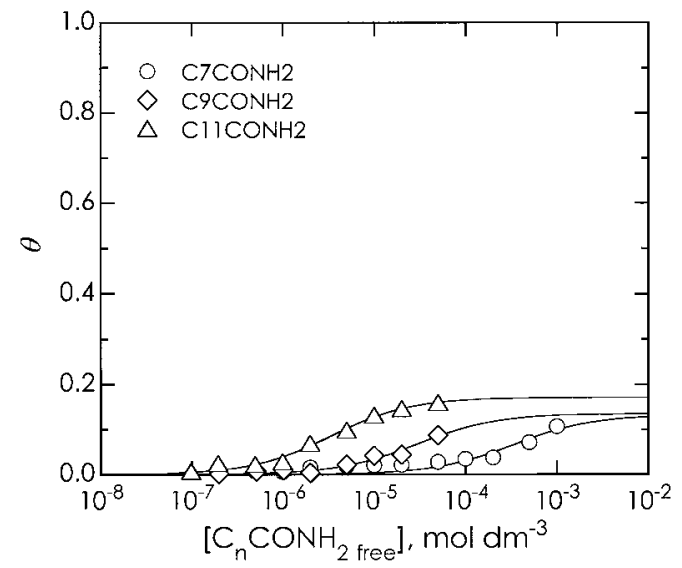

Fig. 8 Dependences of the concentration of free $\mathrm{C}_{n} \mathrm{CONH}_{2}(n=7$, $9,11)$ on the site occupancy, $\theta$, of $\mathrm{C}_{n} \mathrm{CONH}_{2}$ in BSA. Like the $\mathrm{C}_{\mathrm{n}} \mathrm{NH}_{2}$, the $\mathrm{C}_{\mathrm{n}} \mathrm{CONH}_{2}$ also only slightly decreased the fluorescence intensity of the ANS bound to BSA even at their saturated concentrations. $\mathrm{C}_{\mathrm{n}} \mathrm{NH}_{2}$ and $\mathrm{C}_{\mathrm{n}} \mathrm{CONH}_{2}$ are classified as group-III analogues.

values of $\eta$ and $K$. For group-II and group-III, Eq. (1) is reduced to the following form.

$$
\theta=\frac{\eta_{1} K_{1}\left[\mathrm{C}_{\mathrm{n}} \mathrm{X}_{\text {free }}\right]}{1+K_{1}\left[\mathrm{C}_{\mathrm{n}} \mathrm{X}_{\text {free }}\right]}
$$

The $\eta$ and $K$ values obtained from the best fitted curves are listed in Table 1 for group-I and Table 2 for group-II and groupIII analogues. From these results, one can conclude that the fractions of $40 \%$ and $60 \%$ for site- 1 and site-2, respectively, are reasonable assignments. The ANS on site- 1 can be displaced by both group-I and group-II analogues, whereas the ANS on site-2 can be displaced only by the group-I analogues. Because the number of fluorescence-active binding sites in a BSA was four, as estimated from the Scatchard plot in Fig. 2, the values of site$1(40 \%)$ and site-2 $(60 \%)$ correspond to the average number of 1.6 and 2.4 sites, respectively, in a BSA. Two different types of the ANS binding sites were also reported for human serum albumin (HSA) by Bagatolli et al. using phase modulation fluorescence spectroscopy. ${ }^{6}$ The fractions of these two sites in a HSA were $31 \%$ and $69 \%$, respectively. They also reported that only the ANS molecules bound to site-1 were displaced by other ligand like a diazepam. More importantly, the difference of the binding affinity between the two sites decreased with the decrease of the alkyl chain-length of the $\mathrm{C}_{\mathrm{n}} \mathrm{COOH}$ as shown in Fig. 4 and Table 1. This result indicates that the hydrophobicity is also an important factor to differentiate the binding properties of the two types of the binding sites.

In the case of the group-III analogues, both the numbers of the binding sites and the binding constants were lower than those of group-I and group-II analogues. It indicates that the group-III analogues scarcely displaced the ANS ions on BSA at all. However, this does not indicate that these analogues are incapable of interaction with BSA, because a variety of cationic detergents bind to BSA with large binding numbers exceeding 100 ions on a BSA. ${ }^{28}$ One possible cause of this lack of displacement may be that cationic alkane analogues do not share the fluorescence-active binding site with anionic ANS ions, but they do bind to the fluorescence-inactive sites in BSA. As reported by Kolb and Weber ${ }^{26}$ and Valsami, ${ }^{27}$ more than ten fluorescence-inactive ANS binding sites were identified by 
Table 1 Estimated binding parameters of group-I

\begin{tabular}{ccccccc}
\hline Group & $\mathrm{C}_{\mathrm{n}} \mathrm{X}$ & $n$ & $\eta_{1}$ & $K_{1}$ & $\eta_{2}$ & $K_{2}$ \\
\hline Group-I & $\mathrm{C}_{\mathrm{n}} \mathrm{COOH}$ & 5 & 0.37 & $8.9 \times 10^{1}$ & 0.63 & $1.1 \times 10^{3}$ \\
& & 7 & 0.37 & $7.8 \times 10^{2}$ & 0.63 & $3.7 \times 10^{4}$ \\
& & 9 & 0.28 & $3.1 \times 10^{3}$ & 0.72 & $5.5 \times 10^{5}$ \\
& & 11 & 0.43 & $1.4 \times 10^{4}$ & 0.57 & $1.2 \times 10^{6}$ \\
\hline
\end{tabular}

Table 2 Estimated binding parameters of group-II and group-III

\begin{tabular}{clrcc}
\hline Group & \multicolumn{1}{c}{$\mathrm{C}_{\mathrm{n}} \mathrm{X}$} & $n$ & $\eta_{1}$ & $K_{1}$ \\
\hline \multirow{2}{*}{ Group-II } & $\mathrm{C}_{\mathrm{n}} \mathrm{OH}$ & 8 & 0.41 & $3.7 \times 10^{3}$ \\
& & 10 & 0.38 & $2.9 \times 10^{4}$ \\
& & 12 & 0.33 & $1.9 \times 10^{5}$ \\
& & 7 & 0.43 & $9.7 \times 10^{3}$ \\
& & 9 & 0.32 & $6.7 \times 10^{4}$ \\
& & 11 & 0.36 & $8.6 \times 10^{4}$ \\
Group-III & 8 & 0.15 & $3.6 \times 10^{2}$ \\
& & 10 & 0.04 & $6.5 \times 10^{5}$ \\
& $\mathrm{C}_{\mathrm{n}} \mathrm{NH}_{2}$ & 12 & 0.10 & $1.7 \times 10^{4}$ \\
& & 7 & 0.13 & $3.0 \times 10^{3}$ \\
& & 9 & 0.14 & $6.6 \times 10^{3}$ \\
& $\mathrm{C}_{\mathrm{n}} \mathrm{CONH}_{2}$ & 11 & 0.17 & $3.0 \times 10^{3}$ \\
\hline
\end{tabular}

equilibrium dialysis and potentiometry. These sites can be assigned to the binding sites of group-III analogues labeled as site-3.

There are three types of ANS binding sites in a BSA molecule, as demonstrated by the competitive binding of three different types of alkane analogues in connection with the results of nonfluorometric techniques. The ANS ions bound to the site- 2 of BSA can be displaced only by group-I analogues, whereas the ANS ions on the site- 1 can be displaced by the both group-I and group-II analogues but not by group-III analogues. Only the ANS ions bound to the site- 3 of BSA can be displaced by the group-III analogues, though such displacement cannot be detected by the ANS fluorescence.

At the present experimental condition of $\mathrm{pH} 7.4$, both ANS and group-I analogues $\mathrm{C}_{\mathrm{n}} \mathrm{COOH}$ are negatively charged, and group-III analogues $\mathrm{C}_{n} \mathrm{NH}_{2}$ and $\mathrm{C}_{\mathrm{n}} \mathrm{CONH}_{2}$ are positively charged. The group-II analogues $\mathrm{C}_{n} \mathrm{OH}$ and $\mathrm{C}_{n} \mathrm{CHO}$ have no net charge. Therefore, one would expect that the electrostatic interaction is one of the key factors to differentiate the three types of the binding sites in BSA. Site-2 has a specific affinity to the negative charges. The ANS ions bound to this site can only be displaced by the negatively charged group-I analogues. In contrast, site- 1 has higher affinity to hydrophobicity than to negative charge. The ANS ions bound to this site can be displaced by either group-I or group-II analogues but not by the positively charged group-III analogues. As for the site-3 locations, these sites are considered to be the ionizable side chains of the amino acid residues located at the protein-water interface. Although there are hydrophobic interactions between these sites and ANS ions, the interactions are not as strong as for site-1 and site-2. Therefore, water molecules are easily accessible to the ANS ions bound to the site- 3 in BSA, enough to quench the fluorescence. These sites constitute the third binding sites for hydrophobic ligands. This conclusion suggests that the hydrophobic bindings to these sites are not specific. Nonspecific interactions at multiple uncharged and charged sites are candidates for the site- 3 in BSA.
As shown in the Scatchard plot in Fig. 2, the site-1 and site-2 in BSA cannot be differentiated by the binding of ANS to BSA. On the other hand, the differences of the binding interactions in two sites are most explicit at $\mathrm{C}_{9} \mathrm{COOH}$ and decreased with decreasing the alkyl chain-length, as shown in Fig. 4. The hydrophobicity of $\mathrm{C}_{n} \mathrm{COOH}$ also decreases with decreasing the alkyl chain-length. ANS is more soluble in water than the $\mathrm{C}_{\mathrm{n}} \mathrm{COOH}$ examined. Therefore, we can conclude that suitable hydrophobicity is required to differentiate the site- 1 and site- 2 in BSA.

In conclusion, the competitive binding technique using terminally-substituted alkane analogues provides an easy and useful way to classify the binding modes of the hydrophobic small molecules or ions to proteins.

\section{References}

1. L. Stryer, J. Mol. Biol., 1965, 13, 482.

2. M. Deluca, Biochemistry, 1969, 8, 160.

3. J. J. Ory and L. J. Banaszak, Biophys. J., 1999, 77, 1107.

4. K. Sahu, S. K. Mondal, S. Ghosh, D. Roy, and K. Bhattacharyya, J. Chem. Phys., 2006, 124, 124909.

5. E. C. Santos and A. A. Spector, Biochemistry, 1972, 11, 2299.

6. L. A. Bagatolli, S. C. Kivatinitz, F. Aguilar, M. A. Soto, P. Sotomayer, and G. D. Fidelio, J. Fluoresc., 1996, 6, 33.

7. S. Verela, S. Macho, and J. Minones, J. Pharm. Sci., 1992, 81,842 .

8. N. A. Avdulov, S. V. Chochina, V. A. Daragan, F. Schroeder, K. H. Maya, and W. G. Wood, Biochemistry, 1996, 35, 340 .

9. N. P. Franks and W. R. Lieb, Nature, 1984, 310, 599.

10. J. S. Johansson, R. G. Eckenhoff, and P. L. Dutton, Anesthesiology, 1995, 83, 316.

11. I. Ueda and A. Suzuki, Biophys. J., 1998, 75, 1052.

12. A. A. Spector, J. Lipid Res., 1975, 16, 165.

13. K. Takehara, H. Kamaya, and I. Ueda, Biochim. Biophys. Acta, 2005, 1721, 124.

14. K. Takehara, I. Ueda, and K. Kamaya, Anal. Sci., 2001, 17, i1543.

15. M. Maruthamuthu and S. Kishore, Colloid Polym. Sci., 1990, $268,938$.

16. D. Matulis and R. Lovrien, Biophys. J., 1998, 74, 422.

17. C. A. Haskard and W. C. Y. Li-Chan, J. Agric. Food Chem., 1998, 46, 2671.

18. J. A. Hamilton, S. Era, S. P. Bhamidipati, and R. G. Reed, Proc. Natl. Acad. Sci. U. S. A., 1991, 88, 2051.

19. S. Curry, H. Mandelkow, P. Brick, and N. P. Franks, Nat. Struct. Biol., 1998, 5, 827.

20. D. Matulis, C. G. Baumann, V. A. Bloomfield, and R. E. Lovrien, Biopolymers, 1999, 49, 451.

21. W. H. Melhuish, J. Phys. Chem., 1961, 65, 229.

22. B. Bhattacharyya and J. Wolff, Arch. Biochem. Biophys., 1975, 167, 264.

23. E. Daniel and G. Weber, Biochemistry, 1966, 5, 1893.

24. D. V. Naik, W. L. Paul, R. M. Threatte, and S. G. Schulman, Anal. Chem., 1975, 47, 267.

25. M. E. Georgiou, C. A. Georgiou, and M. A. Koupparis, Anal. Chem., 1999, 71, 2541.

26. D. A. Kolb and G. Weber, Biochemistry, 1975, 14, 4476.

27. G. N. Valsami, P. E. Macheras, and M. A. Koupparis, Pharm. Res., 1991, 8, 888.

28. K. Aoki and K. Hiramatsu, Anal. Biochem., 1974, 60, 213. 